\title{
A Study on the Bibo Feng Shui of Dong Ri San Mun
}

\author{
Yeon-Su. Park \\ Tong-Myung University \\ pghlee@naver.com
}

\begin{abstract}
This study is a synthetical survey to give digestive look at Korean Buddhism and a definition of Bibo philosophy of Dosun the state monk by summarizing fragmental past study materials. In other words, this study shows through the facts that in what background Korean Buddhism was introduced, how the Bibo philosophy stems from Buddhism influenced the community, how it was settled among the people, and tried to give direction how Korean Buddhism would approach to the public. However, it would be not easy to generalize the results of the study because the study was proceeded in limited application of Bibo philosophy, more academical merit shall be evaluated when study should focused on how Bibo philosophy was applied to various levels. Accordingly, it seems necessary to expand the range and quantity of the study category on further study of Bibo philosophy and looking forward to continual study.
\end{abstract}

Keywords: Zen Buddhism, Dongrisan school, Geomancy, Bibo geomancy, Dosun state monk.

\section{Introduction}

This study has been proceeded with purpose to confirm the detailed and practical application tool and method on Bibo geomancy the great Dosun state monk advocated which was considered ambiguous in Buddhism culture. Also those temples were selected bibo geomancy was applied during the process of constructing and reconstructing new temples repairing old ones on the site of temple to fulfill and complement weakened energy and bad spirit, and it was confirmed that various tools were applied to approve the method.

Main subject of this study was processed through objection of documentary philology and related books, degree treatise and academic dissertations on the basis of previous research, and on site survey was proceeded through selecting temples for which Bibo geomancy of Dosun the state monk was applied for sample research. Some conclusion was produced how the bibo geomancy of Dosun state monk is applying to contemporary life on the basis of results obtained through on site research, and looking forward to establish a chance to provide familiarity and activeness of Buddhistic culture to general public in practical living by getting rid of conservatism and strictness the Buddhism retained through mixture of Bibo geomancy and Buddhistic culture in the future..

\section{Dongrisan school}

\subsection{Zen buddhism}

1 Article history:

Received (February 21, 2019), Review Result (April 26, 2019), Accepted (June 21, 2019) 
Zen Buddhism is a branch of Chinese Buddhism and a creative fruit of combination absorbing Indian Mahayana buddhistic philosophy under leadership of Chinese philosophical culture and Chinese Taoism combined and transformed and gave great influence to the history of East Asian philosophy and culture. Zen buddhism experienced period of preparation, prosperity and fall, founded at 6 kingdom era and flourished in Soo and Dang Dynasty period, and shaped its form.[1]

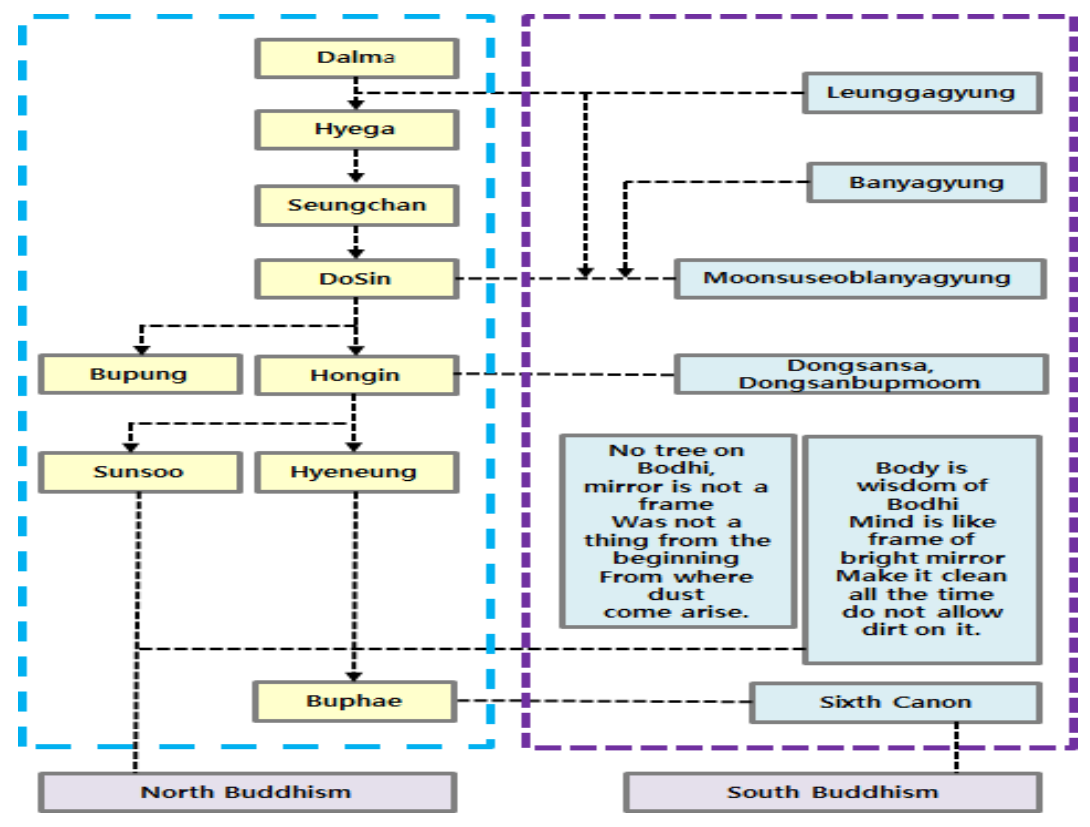

Figure 1. Sun-Jong's Development Flow Diagram[2]

\subsection{Mountain Zen school(Goosansunmoon)}

The term 9 mountain school appears in the history of Koryo(高麗史) for the first time. Such term was contained describing that there was a request for student to take a test every 3 years and such request was allowed. Such kind of term as Dalmagusanmoon(達磨九山門) or Gusansunryo(九山禪侶) were found in later documents, and the document which describes names of 9 schools and its location, and founder of each schools is Sunmoonjosayechameomoon(禪門祖師禮懺儀文).

Table 1. Composition of Goosansunmoon

\begin{tabular}{|c|c|c|}
\hline Mountain school & Location & Founder \\
\hline Gajisan school & Borimsa at Jangheung & Doeui(Chejing) \\
\hline Silsangsan school & Silsangsa at Namwon & Hongchuck \\
\hline Dongrisan schoo & Taeansa at Goksung & Hyechul \\
\hline Sungjusan school & Sungjusa at Boryong(temple site) & Mooyom \\
\hline Sagulsan school & Gulsansa at Gangleung(temple site) & Bumil \\
\hline Sajasan school & Heungryungsa at Youngwol(Bupheung) & Doyoon(Juljung) \\
\hline Bongrimsan school & Bongrimsa at Changwon(temple site) & Hyunwook(Simhee) \\
\hline Soomisan school & Gwangjosa at Haejoo(temple site) & Yeeom \\
\hline
\end{tabular}


\begin{tabular}{|l|l|l|}
\hline Heeyangsan school & Bongamsa at Moongyong & Doheon(Geungyang) \\
\hline
\end{tabular}

\subsection{Dongrisan school}

Dongrisan school or Dongrisan group was one of the 9 schools of zen buddhism instituted at the end of Shilla dynasty through at early Koryo kingdom.

Great monk Hyechul returned and opened his own zen Buddhism Dongrisan school at Taean temple in jookgokmyun, Goksunggun in Junnam province at first year of king Moonsung of Shilla(ad839). The founder priest Hyechul was Park in family name and resident of Gyungjoo. He departed his home early youth and learned scripture Whaeom at Busuksa temple. He went to Dang of China at 5th year of king Hyunduk(ad 813) and learned zen philosophy from Sudangjijang and acquired approval. He stayed for 26 years in Dang of China and returned at the 1st year of king Moonsung and endeavored to enlightening the philosophy at Taean temple and died at 77 years old in the 1st year of king Gyungmoon. The posthumous title for him was Jukin (寂忍).

The most representing temple of the Dongrisan school shall be Taean temple at Goksung in Jollanamdo, Okryong temple at Gwangyang in Jollanamdo, and Dogap temple at youngam in Jollanamdo, and the most representing monks of Dongrisan school were Hyechul, Dosun, Yunda and Gyungbo, and many outstanding leaders of zen philosophy who were very characterized were produced.

\section{Bibo geomancy}

\subsection{Geomancy}

Geomancy is experimental comprehension upon variety and changes of the nature from ancient times. That is the human life has been shaped on natural environment, and human being cultivated and developed each civilization in the nature. Especially in orient, this type of geomantic philosophy was the active method in selecting the housing location and community settlement, and it aimed to select the eternal settlement of the dead, and was a custom to utilize mysterious life vitality of the earth for daily living pursuing the harmony of human and nature, and it contained the concept in which land is mother while comparing to the sky as father.[3]

Geomancy is called Gamyo, Jiri or Jisool in other manner.[4] Folklorist Whang jongchan defines geomancy as "A study which enables utilizing as a indicator in selecting and disposing a lot for housing by organizing various cases followed by weather changes and the use of the land based on the experience from natural environment to be generalized under a specific probability.",[5] and Kim seungwan defines geomancy as " A science of natural environment which perceives the doctrine of the five natural elements in positive and negative influence as basis and considers yong, hyol, sa and soo as elements, and the spirit as fundamental, determines chonri(天理) as a frame, and to promote the harmony of earth and humans, and aims blessing while blaming disaster expelled".[6]

\subsection{Bibo geomancy}

Bibo geomancy is the technical formula which fulfills if certain land or mountain lacks something in geomantic basis. Cases are applied to major elments of geomancy as yongmack, jangpoong, deuksoo and hyonggook. There are several method in fulfilling the misfortune or substitution of the disaster. If yongmaek is weak, make it strong and in good shape by refill the soil by digging the ground. In some case building a new mountain is tried. If the land is a place 
where wind blows so well from right and left, making the fence to block the wind by raising chongyong and baekho intentionally. And if some place is empty, trying complement it by forming the forest is one method among the therapy. Furthermore, even the method of constructing a temple or building pagoda was taken to block bad spirit and to convert it to the soil of good luck.[7]

Water was considered good when it flows surrounding the area or flows along the land without disconnection. If direction of the stream be ugly, it should be changed in good direction. Such kind of method could be used to make a pond for water stationed for while and let it flow again.

If the land looks like a hangjoo shape, a principle that ' there should be water in front of oar of the boat' shall be applied. Accordingly digging for a pond or mast would be erected. If the shape of the land is phoenix, planting paulownia tree or bamboo tree shall be applied. Whatever it lacks the land failed to shape in good look, such deficiency or defects should be supplemented according to situation.

Bibo geomancy corrects by fixing all the geomantic defects by geomantic principles. Due to Bibo geomancy was so flourished in Koryo kingdom, official authority for mountain river bibo office was instituted at the 1st year of king Shinjong. That agency tried to revive the virtue of the land by complementing the geomantic magics around the domestic mountains and streams.

\subsection{Bibo philosophy of Dosun the state monk}

The Bibo philosophy of Dosun the state monk is the thought for natural bibo and bibo pagoda and a philosophy of reality application to promote the welfare of the state and the people through governing the state land so well. The vigor is the Buddhistic Bibo philosophy which tries to establish the prosperity of nation, people and buddha principles by building temple pagoda and image of buddha through selecting fortunate land or important location concerning the bibo among the domestic mountain or stream and practicing various ceremony to prevent all the disaster and misfortune in advance by supplicating the protection of buddha and earthly god and to bring all the blessing and good fortune.[8]

\section{Application manner of Bibo geomancy to modern society}

\subsection{Modern application of Bibo geomancy}

Choosing good location for housing means it blocks the fierce wind by surrounding mountains afar and it cab ne easy to get the water which flows nearby.

If we take a look at Seoul, the city is surrounded by primarily main mount Bookak, Naksan as joachongyong, Inwangsan as Woobaekho, and Namsan as namjoojak. By selecting these location, the city could have plenty of merits receiving much vigor from the ground, and creates a good atmosphere through making the harmony between mountain shape and characters of buildings. So to speak, considering flows of mount and flows of streams and respecting patterns of the land shall be the best way to select a good land.

\subsection{Modern meaning of Bibo geomancy}

Bibo geomancy is divided into yangtaek geomancy on land for housing, yanggi geomancy on the location of village or capital city, and eumtaek geomancy which deals with location of tomb. Basic principle of these three measures concur each other, and yanggi geomancy deals 
with broader area while eumtaek geomancy is represented by theory of spot and it means small portion of land integrated with vitality.

Since Bibo geomancy was introduced, this theory has been applied to lot selection of temple, structure of building and selection of the capital city, and in our country bibo philosophy has been applied limiting to eumtaek geomancy and it was quite neglected to urban planning. From where geomancy in our country was originated? Great scholar Gowoon Choi chiwon once said that wise truth of the kingdom was 'Poongryoo'(geomanctic vigor), and poong of geomancy is the spirit, and ryoo of geomantic vigor is the flow. Soo of the Poongsoo(geomancy) is the flow of the water.[9]

In my view, the spirit of Poongryoo (geomantic vigor) has been developed to a branch of geomantic philosophy. Poet Kim jiha insisted in his poem <Burning thirst> that the vigor shall revive through vitality vein, and asserted to connect the vigor vein is Poongsoo.[10]

Natural environment protection movement is the one of life recovery, and life recovery movement is geomantic moivement. Geomantic movement should be revived for all of us to live. Geomancy(poongsoo) is vigor movement. Life revival crusade and geomantic movement is referred to Poongryoodo in modern times. Poong(風) is long wind, and Ryoo(流) is acquiring the water. Poong means stirring and ryoo is streaming. Poong is divine spirit and ryoo is converting into the vigor. So Poongryoo is sacred life crusade.

In recent times urban planning project is booming. In the past it took several hundreds of years was required to be a city community. However, urban city is made so fast by development of science and machinery technology. In this atmosphere there is definitely natural condition existed. It is the time to establish the know-how for space reform in context of Bibo philosophy which enable us to get rid of life with no planning and chaos.

\section{Conclusion}

Primarily this study surveyed the process how the Buddhism from its birth gave effects to society through Buddhism was accommodated, and among them how the Bibo philosophy of Dongrisan school is influencing to modern society, and tried to look how the philosophy has been connected to our community.

At the age of global community, it seems we've gained a lot through study of the state monk Dosun who revivied Bibo philosophy of Dongrisan school and its identity and peculiarity, and through the study of Bibo philosophy of Dosun in which we could learn international perspectives they had.

By approving fact that Bibo philosophy has been stationed in our mind and living space of daily life by influence of land philosophy especially our tribes had and land culture, and these unique culture of geomancy became the most decisive factor in selecting the lot and gives great influence to overall perception of the space through scientific method, this study would give great contribution to fulfill the bibo geomancy which respect economy and functional merits.

Therefore, as we consider surrounding environment when we select the location, we would make contribution to effective development of national land or lot selection if we accept and accommodate environmental aspects of bibo philosophy in rational viewpoint as the subject of space based on perception on the elements of bibo which were alienated as background elements in our visual structure, and push forward to eco-natural land development for housing, urban planning, land use plan, public facilities and cemetery facility which reflecting the merits of bibo philosophy based on our traditional philosophy and Korean buddhistic philosophy.

Finally, this study is an examination and an inquiry of bibo formula which is applied to Korean traditional society and modern society as the method of bibo philosophy, and this 
proved through sample cases on the fact that bibo philosophy among the Korean buddhistic philosophy even in modern society is closely related to everyday living by finding out the facts which never found before. However, though it shall be not easy to generalize the study results because application range of bibo philosophy was proceeded in limited circumstances, we may assert that more academic values could be affirmed when there should be a study how the bibo philosophy was applied in wide range and scope. Therefore, we should clarify that a new study which is applied with more expanded in range and multiple cases is required in succeeding study on bibo philosophy and we look forward to succeeding research and study.

\section{References}

[1] Yang, Yoon-Seok, A study on the Feng-Shui Location of Chinese Zen Buddhist Temples, Catholic University of Daegu Doctor's Thesis (2015), pp.24-36.

[2] Xia-Hui, A Study on Zen thought in Cultural Landscape design expresssion characteristic, Kookmin University Master's Thesis (2010), pp.14.

[3] Choi, Chang-Jo, Feng-Shui Location of Korea, Seoul, MinUm-Sa (1990), pp.29.

[4] Chen, In-Ho, A Feng-Shui Understanding, Pusan, Se-jong Publishing (1999), pp.1.

[5] Hwang, Jong-Chan, Feng-Shui Location Introduction, Seoul, Good Writing (1999), pp.23.

[6] Kim, Sung-Wan, A Study on the Feng Shui-chihological Analysis of Housing Site Selection of Housing Location, Self-Government Study (1997), Vol. 2, pp.363-387.

[7] Suh, Yoon-Kil, Origin of Do-sun's Geomantic Thoughts, A Buddhist journal, (1976), Vol.13, pp.171-190.

[8] Kim Hak-Beom \& Kim Jung-Tae, A Study on the Landscape Characteristics of the Urban Forest inside of Korea's Historic Cities, Journal of the Korean Traditional Landscape Association (1995), Vol.13 No.2, pp.13-26.

[9] Kim, Seok-Jin, Taesan Zhōuyì Lecture, Grand School of Physical Education (1993), pp.15.

[10] Kim, Gi-Ha, From burning thirst to the sea of life, Dongkwang Publishing House (1991), pp.115. 